\title{
SELERA MASYARAKAT DALAM MENENTUKAN PERUMAHAN DI KABUPATEN SUKOHARJO DENGAN METODE FUZZY-AHP
}

\author{
Setiono ${ }^{1}$, Koosdaryani S. $^{2}$, Suryoto ${ }^{3}$, Nur Ulyanisa ${ }^{4}$ \\ 1 Dosen Teknik Sipil, Fakultas Teknik, Universitas Sebelas Maret, Jln Ir Sutami 36A Surakarta. Telp: (0271)647069. \\ Email: setiono@,ft.uns.ac.id \\ ${ }^{2}$ Dosen Teknik Sipil, Fakultas Teknik, Universitas Sebelas Maret, Jln Ir Sutami 36A Surakarta. Telp: (0271)647069. \\ Email: koosdaryani@gmail.com \\ ${ }^{3}$ Dosen Teknik Sipil, Fakultas Teknik, Universitas Sebelas Maret, Jln Ir Sutami 36A Surakarta. Telp: (0271)647069. \\ Email: suryoto@staff.uns.ac.id \\ ${ }^{4}$ Mahasiswa Teknik Sipil, Fakultas Teknik, Universitas Sebelas Maret, Jln Ir Sutami 36A Surakarta. Telp: (0271)647069. \\ Email: nurulyanisa@gmail.com.
}

\begin{abstract}
The existence of Sukoharjo Regency, which is a thriving region, where several international economic activities, education, health services and the informal sector. With this condition, many immigrants from surrounding area and from outside the area that comes with the purpose of working, school, trading and so on. This situation on the one side raises the problem of housing for the expat community but on the other side is a chance of residential development to provide a means of housing by building the housing needed. The purpose of this research is to know the preference and factors that most people have in choosing housing in Sukoharjo Regency. This research is conducted by collecting primary and secondary data which is the result of the questionnaire to related community. Direct review of the current conditions each housing as well as an assessment of each of the selected factors. Once the data is collected the assessment of the criteria and then assessment of the alternatives and the weighted. This research uses the Furzy-AHP method using Microsoft Excel 2010 Software. Based on research that has been conducted, the legality factor is the most influential factor in choosing housing is 33,22\%. The second influential factor is safety and comfort factor is 24,19\%, then location factor is $21,81 \%$, house fittings factor is $13,58 \%$, and price perceptional factor is $7,27 \%$.
\end{abstract}

\section{Keyword: Housing, Population Preferences, Sukoharjo Regency, Fuzzy-AHP}

\begin{abstract}
Abstrak
Keberadaan Kabupaten Sukoharjo yang merupakan daerah berkembang, dimana beberapa kegiatan perekonomian bertaraf internasional, pendidikan, layanan kesehatan dan sektor informal. Dengan kondisi demikian maka banyak para pendatang dari daerah sekitar maupun dari luar daerah yang datang dengan tujuan bekerja, sekolah, berdagang dan sebagainya. Keadaan ini di satu sisi menimbulkan masalah tempat tinggal bagi masyarakat pendatang, tetapi di sisi lain merupakan peluang pengembangan perumahan untuk menyediakan sarana hunian dengan membangun perumahan-perumahan yang dibutuhkan. Tujuan penelitian ini yaitu untuk mengetahui selera dan faktor yang paling mempengauhi masyarakat dalam memilih perumahan di Kabupaten Sukoharjo. Penelitian ini dilakukan dengan mengumpulkan data primer dan sekunder yang berupa hasil dari kuisioner kepada masyarakat terkait. Peninjauan langsung terhadap kondisi terkini masing-masing perumahan serta pengkajian terhadap masing-masing faktor terpilih. Setelah data terkumpul dilakukan penilian terhadap kriteria dan kemudian penilaian terhadap alternatif dan dilakukan pembobotan. Penelitian ini menggunakan metode Furzy-AHP dengan bantuan Software Microsoft Excel 2010. Berdasarkan penelitian yang telah dilakukan, faktor legalitas merupakan faktor yang paling berpengaruh dalam memilih perumahan yaitu sebesar 33,22\%. Faktor yang berpengaruh kedua yaitu faktor keamanan dan kenyamanan sebesar 24,19\%, kemudian faktor lokasi sebesar 21,81\%, faktor kelengkapan rumah sebesar 13,58\%, dan faktor persepsi harga sebesar 7,27\%.
\end{abstract}

Kata Kunci: Perumahan, Selera Masyarakat, Kabupaten Sukoharjo, Fuzzy-AHP.

\section{PENDAHULUAN}

Permintaan tempat hunian pasti akan meningkat dari tahun ke tahun. Pembangunan permukiman perlu terus ditingkatkan dan dikembangkan secara terpadu, terarah, terencana, dan berkesinambungan. Pada pelaksanaannya perlu mempertimbangkan berbagai aspek sehingga menjadi satu kesatuan fungsional dari wujud tata ruang fisik kehidupan ekonomi dan sosial budaya untuk mendukung dan menjamin kelestarian lingkungan hidup dan meningkatkan kualitas kehidupan manusia dalam berkeluarga dan bermasyarakat. Keberadaan Kabupaten Sukoharjo yang merupakan daerah berkembang, dimana terdapat beberapa kegiatan perekonomian bertaraf internasional, pendidikan, layanan kesehatan and sektor informal. Dengan kondisi demikian maka banyak para pendatang dari daerah sekitar maupun dari luar daerah yang datang ke Sukoharjo dengan tujuan bekerja, sekolah, berdagang dan sebagainya. Keadaan ini di satu sisi menimbulkan masalah tempat tinggal bagi masyarakat pendatang, tetapi di sisi lain merupakan peluang pengembang perumahan untuk menyediakan sarana hunian dengan membangun perumahan-perumahan yang dibutuhkan.

Berdasarkan Undang-Undang No. 1 Tahun 2011 tentang Perumahan dan Pemukiman, perumahan adalah kumpulan rumah sebagai bagian dari perumahan baik perkotaan maupun pedesaan yang dilengkapi dengan prasarana, sarana, dan utilitas umum sebagai hasil upaya pemerintah rumah layak huni. Rumah secara fisik bangunan gedung yang berfungsi sebagai tempat tinggal yang layak huni, sarana pembina keluarga, cerminan 
harkat dan martabat penghuninya, serta aset bagi pemiliknya. Sedangkan perumahan adalah bagian dari lingkungan hunian yang terdiri atas lebih dari satu satuan perumahan yang mempunyai prasarana, sarana, utilitas, serta mempunyai penunjang kegiatan fungsi lain di kawasan perkotaan atau kawasan pedesaaan.

Mardiyati, Juliana, dan Driyani (2016) dalam penelitian "Sistem Penunjang Keputusan Pemilihan Perumahan dengan Menggunakan Metode AHP". Hasil penelitian ini menyebutkan bahwa kriteria harga (50,3\%) merupakan faktor yang berpengaruh dalam pemilihan perumahan. Faktor selanjutnya yaitu lokasi $(25,8 \%)$, model dan tipe $(11,3 \%)$, akses dan transportasi $(12,6 \%)$.

Penentuan lokasi perumahan dipengaruhi oleh faktor-faktor penentu kawasan perumahan seperti yang dikemukakan oleh para ahli. Penentuan lokasi perumahan penting untuk dilakukan karena keberadaaan kawasan perumahan tergantung dari kondisi lokasi sekitar dan lain sebagainya. Faktor penentu lokasi perumahan mampu menjawab alasan kecenderungan lokasi perumahan yang menjauh dari pusat kota menuju kawasan peri-urban (kota dan desa berhimpitan). Oleh karena itu faktor-faktor penentu lokasi perumahan memiliki peran yang berbeda-beda sehingga sangat penting untuk dipahami.

Berdasarkan kajian jurnal dan buku tentang indikator yang mempengaruhi masyarakat dalam memilih lokasi perumahan, penulis melakukan analisis terhadap indikator-indikator yang dapat mempengaruhi masyarakat dalam memilih lokasi perumahan menurut para ahli. Indikator yang telah dianalisis terangkum dalam Tabel 1 berikut:

Tabel 1. Indikator yang Berpengaruh dalam Pemilihan Lokasi Perumahan

\begin{tabular}{|c|c|c|}
\hline Sumber & Indikator & Faktor \\
\hline 1. Goodall & Persepsi Harga & 1. Harga \\
\hline 2. Mu'ammar & & 2. Angsuran \\
\hline Qathafi & & 3. Uang muka \\
\hline 3. Dasra & & 4. Persyaratan memperoleh kredit rumah \\
\hline 1. Komaruddin & Lokasi & 1. Terjangkau oleh trasnportasi umum \\
\hline 2. Lust & & 2. Dekat dengan pusat CBD \\
\hline 3. Departemen & & 3. Infrastruktur jalan yang memadai \\
\hline Pekerjaan Umum & & 4. Fasilitas Umum (Kesehatan, Pendidikan, \\
\hline 4. Dasra & & Olahraga dan Rekreasi) \\
\hline & & 5. Fasilitas peribadatan \\
\hline 1. Prayogo Mirhard & Keamanan dan & 1. Aman dari kriminalitas \\
\hline 2. Mu'ammar & Kenyamanan & 2. Aman dari investasi \\
\hline Qathafi & & 3. Tingkat Polusi \\
\hline & & 4. Kualitas Bangunan \\
\hline 1. Departemen & Fasilitas & 1. Jaringan air bersih \\
\hline Pekerjaan Umum & & 2. Jaringan listrik \\
\hline 2. Dasra & & 3. Drainase \\
\hline & & 4. Persampahan \\
\hline & & 5. Ruang Terbuka Hijau \\
\hline 1. Mu'ammar & Legalitas & 1. Ijin mendirikan bangunan \\
\hline Qathafi & & 2. Sertifikat tanah \\
\hline
\end{tabular}

Metode Fuгzy Analytic Hierarchy Process ( Fuzzy-AHP) merupakan metode analisis yang dikembangkan dari AHP. Walaupun AHP bisa digunakan dalam menangani kriteria kualitatif dan kuantitatif namun furzy-AHP dianggap lebih baik dalam mendeskripsikan keputusan yang samar-samar daripada AHP. Metode furay memiliki kemampuan dalam proses penalaran secara bahasa sehingga dalam perancangannya tidak memelukan persamaan matematika yang rumit sehingga mudah dimengerti, memiliki toleransi terhadap data-data yang tidak tepat, mampu 
memodelkan fungsi-fungsi nonlinier yang sangat kompleks, dapat membangun dan mengaplikasikan pengalaman-pengalaman para pakar secara langsung tanpa harus melalui proses pelatihan, dapat bekerjasama dengan teknik-teknik kendali secara konvensional dan didasarkan pada bahasa alami.

Untuk menentukan derajat keanggotaan pada F-AHP, digunakan aturan fungsi dalam bentuk bilangan furay segitiga atau Triangular Fuzzy Number (TFN). Bilangan Triangular Fuz:y merupakan teori hmpunan fuz:y yang membantu dalam pengukuran yang berhubungan dengan penilaian subjektif manusia memakai bahasa atau linguistik. Inti dari fuz:y AHP terletak pada perbandingan berpasangan yang digambarkan dengan skala rasio yang berhubungan dengan skala fuzzy.

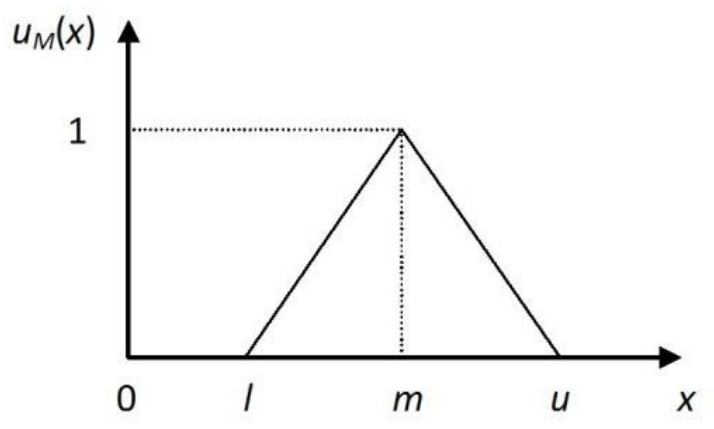

Gambar 1. Skala Segitiga Fuzzy

TFN disimbolkan dengan $\widetilde{M}=(l, m, u)$, dimana $l \leq m \leq u_{\text {dan }} l$ adalah nilai terendah, $m$ adalah nilai tengah, $u$ adalah nilai teratas.

Chang (1996) mendefinisikan nilai intensitas AHP ke dalam skala fuzzy segitiga yaitu membagi tiap himpunan furzy dengan 2, kecuali untuk intensitas kepentingan 1. Skala furzy segitiga yang digunakan Chang dapat dilihat pada tabel berikut ini:

Table 2. Skala Nilai Fur:y Segitiga (Chang, 1996)

\begin{tabular}{clcc}
\hline $\begin{array}{c}\text { Intensitas } \\
\text { Kepentingan AH } \\
\mathrm{P}\end{array}$ & \multicolumn{1}{c}{ Himpunan Linguistik } & $\begin{array}{c}\text { Triangular Fuziy } \\
\text { Number (TFN) }\end{array}$ & Reciprocal (Kebalikan) \\
\hline 1 & $\begin{array}{l}\text { Perbandinagan elemen yang } \\
\text { sama (just equaly) }\end{array}$ & $(1,1,1)$ & $(1,1,1)$ \\
\hline 2 & Pertengahan(Intermediate) & $(1 / 2,1,3 / 2)$ & $(2 / 3,1,2)$ \\
\hline 3 & $\begin{array}{l}\text { Elemen satu cukup penting dari yang } \\
\text { lainnya (moderately important) }\end{array}$ & $(1,3 / 2,2)$ & $(1 / 2,2 / 3,1)$ \\
\hline 4 & $\begin{array}{l}\text { Pertengahan (Intermediate) elemen } \\
\text { yang satu lebih cukup penting dari } \\
\text { yang lainnya. }\end{array}$ & $(3 / 2,2,5 / 2)$ & $(2 / 5,1 / 2,2 / 3)$ \\
\hline 5 & $\begin{array}{l}\text { Elemen satu kuat pentingnya dari } \\
\text { yang lain (Strongly Important) }\end{array}$ & $(2,5 / 2,3)$ & $(1 / 3,2 / 5,1 / 2)$ \\
\hline 6 & Pertengahan (Intermediate) & $(5 / 2,3,7 / 2)$ & $(2 / 7,1 / 3,2 / 5)$ \\
\hline 7 & $\begin{array}{l}\text { Elemen satu lebih kuat pentingnya } \\
\text { dari yang lainnya (Very Strong) }\end{array}$ & $(3,7 / 2,4)$ & $(1 / 4,2 / 7,1 / 3)$ \\
\hline 8 & Pertengahan (Intermediate) & $(7 / 2,4,9 / 2)$ & $(2 / 9,1 / 4,2 / 7)$ \\
\hline 9 & $\begin{array}{l}\text { Elemen satu mutlak lebih penting } \\
\text { dari yang lainnya (Exremely Strong) }\end{array}$ & $(4,9 / 2,9 / 2)$ & $(2 / 9,2 / 9,1 / 4)$ \\
\hline
\end{tabular}

\section{METODE}

Penelitian ini dilakukan dengan mengumpulkan data primer dan sekunder yang berupa hasil dari kuisioner kepada masyarakat perumahan di Kabupaten Sukoharjo. Peninjauan langsung terhadap kondisi terkini masingmasing perumahan serta pengkajian terhadap masing-masing faktor yang dipilih. Setelah data terkumpul, dilakukan penilaian terhadap kriteria dan kemudian penilaian terhadap alternatif dan diperlukan pembobotan. Untuk itu, penelitian ini menggunakan metode fursy-AHP dengan bantuan software Microsoft Excel $20 l 0$.

Adapun metode yang digunakan untuk mencapai tujuan dalam penelitian ini diuraikan sebagai berikut: 
1. Mengidentifikasi masalah.

2. Studi pustaka dan pengumpulan data.

3. Analisis dan pembahasan kriteria penilaian sesuai preferensi konsumen.

4. Melakkukan penyebaran kuisioner untuk pembobotan masing-masing kriteria.

5. Melakukan perhitungan bobot faktor-faktor yang berpengaruh dan menjadi prioritas untuk memilih perumahan terbaik menggunakan metode Fuzzy-AHP.

6. Membuat prioritas pemilihan prumahan yang terbaik dari kriteria-kriteria yang ada.

\section{HASIL DAN PEMBAHASAN}

\section{Data yang Digunakan}

Berdasarkan sasaran studi, maka data yang dibutuhkan dalam studi ini meliputi data primer dan data sekunder. Pengumpulan data primer dilakukan dengan cara observasi dan penyebaran kuisioner terhadap masyarakat perumahan di Kabupaten Sukoharjo. Sedangkan data sekunder yang dimaksud adalah data yang berasal dari instansi yang berbentuk buku laporan, jurnal, peraturan-peraturan, dan sebagainya. Penelitian ini menggunakan 15 responden dari 9 perumahan yang berada di Kabupaten Sukoharjo. Adapun data responden sebagai berikut:

Tabel 3. Data Responden

\begin{tabular}{|l|l|l|l|}
\hline No. & Nama & Pekerjaan & Perumahan \\
\hline 1 & Intani Asih Wonodewi & Wiraswasta & Central Park Gedangan \\
\hline 2 & Ninik Suryani & Analisis Kesehatan & Griya Edelweis \\
\hline 3 & Setiawan Budi Santoso & Polri & Griya Sentosa Gedangan \\
\hline 4 & Andika S. B. Putra & Karyawan Swasta & Griya Sentosa Gedangan \\
\hline 5 & Umi Sofuro & Ibu Rumah Tangga & Grand Residence Gadingan \\
\hline 6 & Langgeng Muryono & Asisten Lab. & Grand Residence Gadingan \\
\hline 7 & Fitri & Ibu Rumah Tangga & Taman Anggrek \\
\hline 8 & Syndhi & Ibu Rumah Tangga & Taman Anggrek \\
\hline 9 & Widiyanto & PNS & Jombor Permai \\
\hline 10 & Sugiman & Swasta & Griya Fajar Pesona \\
\hline 11 & Ahmad Novianto Saputra & Wiraswasta & Tirtamaya Residence \\
\hline 12 & Agustri Wibowo & Karyawan Swasta & Tirtamaya Residence \\
\hline 13 & Heru Susanto & Wiraswasta & Springville Residence \\
\hline 14 & SN & Karyawan Swasta & Central Park Gedangan \\
\hline 15 & Bambang Nugroho & Karyawan Swasta & Griya Edelweis \\
\hline
\end{tabular}

\section{Analisis Perhitungan}

1. Menyusun matriks perbandingan berpasangan dari hasil kuesioner, kemudian menghitung vektor prioritas (Eigenvector) untuk kriteria utama.

Tabel 4. Matriks Perbandingan Berpasangan

\begin{tabular}{l|ccccc}
\hline \multicolumn{1}{c|}{ Kriteria } & harga & lokasi & aman nyaman & kelengkapan & legalitas \\
\hline harga & 1 & $1 / 3$ & $1 / 3$ & $1 / 2$ & $1 / 4$ \\
lokasi & 3 & 1 & $1 / 2$ & $1 / 3$ & $1 / 2$ \\
aman nyaman & 3 & 2 & 1 & $1 / 2$ & $1 / 3$ \\
kelengkapan & 2 & 3 & 2 & 1 & $1 / 2$ \\
legalitas & 4 & 2 & 3 & 2 & 1 \\
\hline total & 13.00 & 8.33 & 6.83 & 4.33 & 2.58 \\
\hline
\end{tabular}

Menjumlahkan nilai yang terdapat dalam satu kolom dan diberi nama total. Kemudian membagi setiap entri matriks dengan total kolomnya masing-masing dan menjumlahkan nilai yang terdapat dalam satu baris. Ratarata dari entri matriks yang terdapat dalam satu baris dihitung dan hasilnya dinyatakan sebagai faktor prioritas. 
Tabel 5. Hasil Pembagian Matrik dengan Total Kolom

\begin{tabular}{l|rrrrr|r|c}
\hline Kriteria & harga & lokasi & $\begin{array}{c}\text { aman } \\
\text { nyaman }\end{array}$ & kelengkapan & legalitas & jml & $\begin{array}{c}\text { faktor } \\
\text { prioritas }\end{array}$ \\
\hline harga & 0.08 & 0.04 & 0.05 & 0.12 & 0.10 & 0.38 & 0.08 \\
lokasi & 0.23 & 0.12 & 0.07 & 0.08 & 0.19 & 0.69 & 0.14 \\
aman nyaman & 0.23 & 0.24 & 0.15 & 0.12 & 0.13 & 0.86 & 0.17 \\
kelengkapan & 0.15 & 0.36 & 0.29 & 0.23 & 0.19 & 1.23 & 0.25 \\
legalitas & 0.31 & 0.24 & 0.44 & 0.46 & 0.39 & 1.84 & 0.37 \\
\hline total & 1.00 & 1.00 & 1.00 & 1.00 & 1.00 & 5.00 & 0.63 \\
\hline
\end{tabular}

2. Menghitung Nilai Eigen (eigenvalue)

a. Mengalikan matriks perbandingan berpasangan dengan faktor prioritas dan hasilnya dinyatakan sebagai faktor jumlah bobot.

$$
\left[\begin{array}{ccccc}
1 & 1 / 3 & 1 / 3 & 1 / 2 & 1 / 4 \\
3 & 1 & 1 / 2 & 1 / 2 & 1 / 2 \\
3 & 2 & 1 & 1 / 2 & 1 / 3 \\
2 & 3 & 2 & 1 & 1 / 2 \\
4 & 2 & 3 & 2 & 1
\end{array}\right] \times\left[\begin{array}{c}
0,08 \\
0,14 \\
0,17 \\
0,25 \\
0,37
\end{array}\right]=\left[\begin{array}{c}
0,39 \\
0,72 \\
0,92 \\
1,34 \\
1,96
\end{array}\right]
$$

b. Membagi entri nilai dari faktor jumlah bobot dengan entri yang berpasangan dari faktor prioritas dan hasilnya dinyatakan sebagai bobot prioritas (eigenvalue).

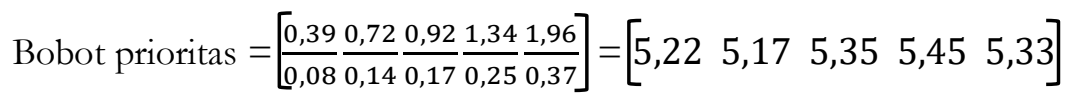

3. Menghitung rasio konsistensi (CR)

a. Menghitung rata-rata dari nilai bobot prioritas dan hasilnya dinotasikan dengan $\lambda_{\text {maks }}$ atau dapat disebut dengan nilai eigen maksimal.

$$
\begin{aligned}
\lambda_{\text {maks }} & =(0,08 * 13)+(0,14 * 8,33)+(0,17 * 6,83)+(0,25 * 4,33)+(0,37 * 2,58) \\
& =5,33
\end{aligned}
$$

b. Menghitung Consistency Index (CI) dengan $n$ benilai 5 karena ada 5 kriteria.

$$
C I=\frac{\lambda_{m a k s}-n}{n-1}=\frac{5,33-5}{5-1}=0,08
$$

c. Menghitung Consistency Rasio (CR) dengan rumus sebagai berikut.

Tabel 6. Random Consistency Index (RI)

\begin{tabular}{|c|c|c|c|c|c|c|c|c|c|}
\hline $\mathrm{n}$ & 2 & 3 & 4 & 5 & 6 & 7 & 8 & 9 & 10 \\
\hline $\mathrm{RI}$ & 0 & 0,58 & 0,90 & 1,12 & 1,24 & 1,32 & 1,41 & 1,45 & 1,51 \\
\hline
\end{tabular}

$C R=\frac{C I}{R I}$ dengan $n=5$, maka $R I=1,12=\frac{0,08}{1,12}=0,07$

Matriks perbandingan berpasangan tersebut dinyatakan konsisten karena $C R \leq 0,1$. Untuk 15 kuisioner lainnya dlakukan langkah yang sama untuk menguji kekonsistenan matriks perbandingan berpasangan antar kriteria. Jika seluruh data sudah konsisten, maka akan dilanjutkan dengan menghitung rata-rata 
geometrik dari setiap kriteria dan subkriteria. Matriks fuzzy perbandingan berpasangan untuk antar kriteria utama.

4. Mengkonversi skala linguistic AHP menjadi Triangular Fuг:y Number (TFN).

Mengubah penilaian responden dari skala linguistic menjadi TFN. Bentuk dari TFN adalah $(l, m, u)$ sebagai bilangan fursy. Tabel 5 Menunjukkan hasil konversi matriks perbandingan penilaian responden terhadap faktor utama pemilihan perumahan.

Tabel 7. Konversi Nilai TFN

\begin{tabular}{|c|c|c|c|c|c|c|c|c|c|c|c|c|c|c|c|}
\hline & \multicolumn{3}{|c|}{ harga } & \multicolumn{3}{|c|}{ lokasi } & \multicolumn{3}{|c|}{ aman nyaman } & \multicolumn{3}{|c|}{ kelengkapan } & \multicolumn{3}{|c|}{ legalitas } \\
\hline harga & 1.0 & 1.0 & 1.0 & 0.5 & 0.7 & 1.0 & 0.5 & 0.7 & 1.0 & 0.7 & 1.0 & 2.0 & 0.4 & 0.5 & 0.7 \\
\hline lokasi & 1.0 & 1.5 & 2.0 & 1.0 & 1.0 & 1.0 & 0.7 & 1.0 & 2.0 & 0.5 & 0.7 & 1.0 & 0.7 & 1.0 & 2.0 \\
\hline aman nyaman & 1.0 & 1.5 & 2.0 & 0.5 & 1.0 & 1.5 & 1.0 & 1.0 & 1.0 & 0.7 & 1.0 & 2.0 & 0.5 & 0.7 & 1.0 \\
\hline kelengkapan & 0.5 & 1.0 & 1.5 & 1.0 & 1.5 & 2.0 & 0.5 & 1.0 & 1.5 & 1.0 & 1.0 & 1.0 & 0.7 & 1.0 & 2.0 \\
\hline legalitas & 1.5 & 2.0 & 2.5 & 0.5 & 1.0 & 1.5 & 1.0 & 1.5 & 2.0 & 0.5 & 1.0 & 1.5 & 1.0 & 1.0 & 1.0 \\
\hline
\end{tabular}

5. Menghitung nilai Fur:y Syntethic Extent (FSE).

Perhitungan nilai FSE bertujuan untuk melakukan penilaian bobot tiap faktor dan subfaktor terhadap tujuan utama dari hirarki yaitu menentukan faktor dan subfaktor serta pembobotan pemilihan perumahan. Berikut merupakan tahap perhitungan nilai FSE pada faktor utama.

a. Perhitungan jumlah komponen TFN yaitu $(1, \mathrm{~m}, \mathrm{u})$ secara horizontal ditunjukkan dalam Tabel 8 .

Tabel 8. Hasil Penjumlahan TFN secara Horizontal

\begin{tabular}{|l|r|r|r|}
\hline & \multicolumn{1}{|c|}{$\sum \mathrm{l}$} & \multicolumn{1}{c|}{$\sum \mathrm{m}$} & \multicolumn{1}{c|}{$\sum \mathrm{u}$} \\
\hline harga & 3.1 & 3.8 & 5.7 \\
\hline lokasi & 3.8 & 5.2 & 8.0 \\
\hline aman nyaman & 3.7 & 5.2 & 7.5 \\
\hline kelengkapan & 3.7 & 5.5 & 8.0 \\
\hline legalitas & 4.5 & 6.5 & 8.5 \\
\hline jumlah & 18.7 & 26.2 & 37.7 \\
\hline
\end{tabular}

Contoh perhitungan:

$$
\begin{aligned}
\sum 1 & =\mathrm{Lc} 11+\mathrm{Lc} 12+\mathrm{Lc} 13+\mathrm{Lc} 14+\mathrm{Lc} 15 \\
& =1+0,5+0,5+0,7+0,4 \\
& =3,1
\end{aligned}
$$

b. Perhitungan nilai invers penjumlahan TFN

$$
\begin{aligned}
{\left[\sum_{i=1} \sum_{j=1} M_{g i}^{j}\right]^{-1}=} & \left(\frac{1}{\sum_{i-1}^{n} u_{i}}, \frac{1}{\sum_{i-1}^{n} m_{i}}, \frac{1}{\sum_{i-1}^{n} l_{i}}\right) \\
& =\left(\frac{1}{37,7}, \frac{1}{26,2}, \frac{1}{18,7}\right) \\
& =(0,027 ; 0,038 ; 0,053)
\end{aligned}
$$

c. Perhitungan nilai sintesis fuzzy $(\mathrm{Si})$

Contoh perhitungan:

$$
\begin{aligned}
\mathrm{S}_{\mathrm{i}} & =\sum_{j=1} M_{g i}^{i} \oplus\left[\sum_{i=1} \sum_{j=1} M_{g i}^{j}\right]^{-1} \\
& =3,1 * 1 / 37,7 \\
& =0,081
\end{aligned}
$$

Hasil perhitungan nilai sintesis fuzzy dapat dilihat pada Tabel 9.

Tabel 9. Hasil Perhitungan Nilai Sintesis Fur:y 


\begin{tabular}{|l|r|r|r|}
\hline & \multicolumn{1}{l|}{ l } & \multicolumn{1}{l|}{$\mathrm{m}$} & $\mathrm{u}$ \\
\hline Harga & 0.081 & 0.146 & 0.302 \\
\hline Lokasi & 0.102 & 0.197 & 0.427 \\
\hline Aman nyaman & 0.097 & 0.197 & 0.400 \\
\hline Kelengkapan & 0.097 & 0.210 & 0.427 \\
\hline Legalitas & 0.119 & 0.248 & 0.454 \\
\hline
\end{tabular}

6. Degree of Possibility

Perbandingan ini digunakan untuk nilai bobot pada masing-masing kriteria dengan nilai minimumnya. Vektor bobot dilakukan agar mempermudah interpretasi yang diperoleh dari nilai minimum perbandingan bilangan fuzzy konveks. Setelah perhitungan degree of possibility, tahap berikutnya adalah menentukan nilai minimum dari perbandingan nilai degree of possibility untuk tiap baris faktor yang digunakan dalam tahap normalisasi bobot. Kemudian totalnya tersebut digunakan sebagai pembagi dalam proses normalisasi.

Dimana $\mathrm{x}$ dan y merupakan nilai-nilai pada sumbu dan fungsi keanggotaan tiap faktor. Persamaan diatas dapat didefinisikan sebagai berikut:

$$
V\left(M_{2} \geq M_{1}\right)=\left\{\begin{array}{c}
1 ; \text { jika } m_{2} \geq m_{1} \\
0 ; j i k a l_{1} \geq u_{2} \\
\frac{l_{1}-u_{2}}{\left(m_{2}-u_{2}\right)-\left(m_{1}-l_{1}\right)} ; \text { untuk kondisi lainnya }
\end{array}\right.
$$

Vsc1 $\geq($ Vsc2, Vsc3, Vsc 4, Vsc 5)

Vsc1 $\geq$ Vsc2= $0,80 \quad$, diperoleh sbb:

$=\frac{l 2-u 1}{(m 1-u 1)-(m 2-l 2)}=\frac{0,102-0,302}{(0,146-0,302)-(0,197-0,102)}=\frac{-0,201}{-0,252}=0,80$

Vsc1 $\geq \operatorname{Vsc} 3=0,80 \quad$, diperoleh sbb:

$=\frac{l 3-u 1}{(m 1-u 1)-(m 3-l 3)}=\frac{0,097-0,302}{(0,146-0,302)-(0,197-0,097)}=\frac{-0,205}{-0,256}=0,80$

Rekapitulasi hasil perhitungan degree of possibility dapat dilihat pada Tabel 10.

Tabel 10. Hasil Perhitungan Degree of Possibility

\begin{tabular}{|l|r|r|r|r|r|r|}
\hline & harga & lokasi & aman nyaman & kelengkapan & legalitas & \multicolumn{1}{l|}{ min } \\
\hline harga & & 0.80 & 0.80 & 0.76 & 0.64 & 0.64 \\
\hline lokasi & 1.00 & & 1.00 & 0.96 & 0.86 & 0.86 \\
\hline aman nyaman & 1.00 & 1.00 & & 0.96 & 0.85 & 0.85 \\
\hline kelengkapan & 1.00 & 1.00 & 1.00 & & 0.89 & 0.89 \\
\hline legalitas & 1.00 & 1.00 & 1.00 & 1.00 & & 1.00 \\
\hline \multicolumn{7}{|c|}{ Total } \\
\hline
\end{tabular}

7. Normalisasi bobot

Tahap akhir dari Fuгsy AHP adalah tahap normalisasi bobot. Jika vector bobot tersebut dinormalisasikan maka nilai yang diperoleh dalam bobot vector menjadi analog bobot dan terdiri dari bilangan non-fuz: $y$. Sehingga diketahui nilai bobot kriteria utama.

Contoh perhitungan:

$$
\begin{aligned}
& \operatorname{CRISP}\left(d_{i}\right)=\frac{d^{\prime}{ }_{i}}{\sum_{i=1}^{n} d^{\prime} i} \\
& \operatorname{CRISP}\left(d_{l}\right)=\frac{d^{\prime}{ }_{1}}{\sum_{i=1}^{n} d_{1}}
\end{aligned}
$$




$$
\begin{aligned}
& =\frac{0,64}{4,24} \\
& =15 \%
\end{aligned}
$$

8. Perhitungan Rata-Rata Total Pembobotan

Cara yang digunakan dalam perhitungan ini yaitu menggunakan perhitungan rata-rata tertimbang/terbobot. Rata-rata tertimbang/terbobot (weighted average) adalah rata-rata yang dihitung dengan memperhitungkan timbangan/bobot untuk setiap datanya. Perhitungan rata-rata total pembobotan dihitung menggunakan rumus berikut:

$\bar{x}=\frac{\sum_{i=1}^{n} x_{i} w_{i}}{\sum_{i=1}^{n} w_{i}}$

\section{Keterangan:}

$\bar{x}=$ rata-rata tertimbang

$x_{i}=$ nilai data ke- $i$

$w_{i}=$ bobot data ke- $i$

$n=$ jumlah data

Contoh perhitungan:

$$
\bar{x}=\frac{\sum_{i=1}^{n} x_{i} w_{i}}{\sum_{i=1}^{n} w_{i}}=\frac{39.99}{100}=39.99 \%
$$

\section{SIMPULAN}

1. Pada faktor utama, faktor legalitas merupakan faktor yang paling berpengaruh dalam memilih perumahan yaitu sebesar 33,22\%. Faktor yang berpengaruh kedua yaitu faktor keamanan dan kenyamanan sebesar $24,19 \%$, kemudian faktor lokasi sebesar 21,81\%, faktor kelengkapan rumah sebesar 13,58\%, dan faktor persepsi harga sebesar $7,27 \%$.

2. Pada faktor persepsi harga, subfaktor harga memiliki bobot nilai tersebesar yaitu 39,99\%. Kemudian subfaktor uang muka sebesar $24,31 \%$, subfaktor angsuran sebesar $17,88 \%$, dan yang terkecil adalah subfaktor persyaratan memperoleh kredit sebesar $17,82 \%$.

3. Pada faktor lokasi, subfaktor dengan bobot nilai terbesar yaitu fasilitas peribadatan sebesar 33,08\%. Kemudian subfaktor fasilitas umum sebesar $22,97 \%$, subfaktor infrastruktur jalan yang memadai sebesar $18,88 \%$, subfaktor dekat dengan pusat CBD sebesar 13,93\%, dan subfaktor terjangkau oleh trasportasi umum sebesar $11,14 \%$.

4. Subfaktor terbesar dalam faktor keamanan dan kenyamanan adalah aman dari kriminalitas sebesar 48,92\%. Kemudian subfaktor kualitas bangunan sebesar $22,26 \%$, subfaktor tingkat polusi sebesar $18,67 \%$, subfaktor aman dari investasi sebesar 10,15\%.

5. Pada faktor kelengkapan rumah subfaktor dengan nilai terbesar yaitu jaringan air bersih sebesar $24,79 \%$. Kemudian subfaktor jaringan listrik sebesar $22,79 \%$, subfaktor drainase sebesar $19,51 \%$, subfaktor persampahan sebesar $17,65 \%$, subfaktor ruang terbuka hijau sebesar $15,27 \%$.

6. Pada faktor legalitas, subfaktor sertifikat tanah memiliki bobot nilai yang lebih besar dari subfaktor ijin mendirikan bangunan. Subfaktor sertifikat tanah memiliki bobot nilai sebesar $64,56 \%$ dan subfaktor ijin mendirikan tanah memiliki bobot nilai sebesar 35,56\%.

\section{REFERENSI}

Chang, D.Y. 1996. Application of The Extent Analysis Method on Fursy AHP. European Journal of Operation Research 95: 649-655.

Johan Silas. 1985. Perumahan dan Permukiman (Buku 1 dan 2). Surabaya : Jurusan Arsitektur, FTSP-ITS.

Kalesaran, R., Mandagi, R., \& Waney, E. (2013). Analisa Faktor-Faktor Yang Mempengaruhi Keputusan Konsumen Dalam Pemilihan Lokasi Perumahan Di Kota Manado. Jurnal Ilmiah Media Engineering, 3(3), 99064. 
Komaruddin. 1997. Menelusuri Pembangunan Perumahan dan Permukiman. Jakarta: Yayasan REI - PT Rakasindo.

Luhst. K. M. 1997. Real Estate Evaluation. USA: , Principles Aplication Press.

MARDIYATI, S., JULIANA, \& DRIYANI, D. (2016). Sistem Penunjang Keputusan Pemilihan Perumahan Dengan Metode AHP. Faktor Exacta, 8(2), 63-71.

Putra, B. Z., \& Rahayu, S. (2015). Faktor-Faktor Yang Mempengaruhi Pemilihan Perumahan Dan Tipe Rumah Di Perumahan Bukit Emerald. Teknik PWK (Perencanaan Wilayah Kota), 4(4), 681-691.

Saaty, Thomas L. 1993. Pengambilan Keputusan Bagi Para Pemimpin. Jakarta: Pustaka Binaman Presindo.

Undang-Undang Republik Indonesia Nomor 1 Tahun 2011 tentang Perumahan dan Kawasan Permukiman 